\title{
Molecular Characterization of Natural Hybrids of Phytophthora nicotianae and P. cactorum
}

\author{
Peter J. M. Bonants, Marjanne Hagenaar-de Weerdt, Willem A. Man in 't Veld, and Robert P. Baayen
}

First and second authors: Plant Research International, PO Box 16, 6700 AA Wageningen, the Netherlands; third and fourth authors: Plant Protection Service, PO Box 9102, 6700 HC Wageningen, the Netherlands.

Accepted for publication 3 May 2000.

\begin{abstract}
Bonants, P. J. M., Hagenaar-de Weerdt, M., Man in 't Veld, W. A., and Baayen, R. P. 2000. Molecular characterization of natural hybrids of Phytophthora nicotianae and P. cactorum. Phytopathology 90:867-874.

Hybrid isolates of Phytophthora nicotianae $\times$ P. cactorum from five different hosts (Cyclamen, Lavandula, Lewisia, Primula, and Spathiphyllum spp.) were identified by their atypical morphology and their well-defined heterozygous isozyme patterns. The hybrid nature of these isolates was tested by restriction fragment length polymorphism analysis of the internal transcribed spacer (ITS) region of rDNA, generating fragments typical for both $P$. nicotianae and $P$. cactorum. In hybrid isolates, polymerase chain reactions (PCR) with primers derived from unique parts of the ITS region (ITS-PCR) of both species yielded a combination of unique amplicons typical of both parental species. Eleven hybrid

isolates, three isolates of each parental species and two atypical isolates from Rhododendron and Idesia spp. close to P. cactorum, were analyzed for amplified fragment length polymorphisms (AFLP). Consistent differences in AFLP patterns existed among the hybrid isolates, strongly indicating that these hybrids have arisen from independent hybridization events between $P$. nicotianae and $P$. cactorum. The two atypical isolates morphologically resembling $P$. cactorum were identical to the latter species in ITS-restriction fragment length polymorphism and response to the specific PCR primers but were intermediate between $P$. nicotianae $\times$ $P$. cactorum and $P$. cactorum in isozyme profiles and AFLP patterns. Since the introduction of hydroponic systems in greenhouses in the Netherlands, outbreaks of Phytophthora diseases are occurring in previously unaffected host species. This may be due to interspecific hybridization events resulting in novel pathogenic behavior.
\end{abstract}

The Oomycete genus Phytophthora, composed of some of the most destructive plant pathogens, causes considerable economic losses to food crops and ornamentals every year (13). More than 50 species have been described, and new species are still being discovered (16). Some species are highly specialized to a single host; P. fragariae var. rubi, for example, is only infectious to Rubus idaeus. Other species, such as $P$. nicotianae, $P$. cactorum, and $P$. palmivora, have wide host ranges. Several species have been placed on quarantine lists in and outside Europe.

Species identification is based primarily on the shape of the sporangia and the morphological features of the sexual structures. Other criteria widely used to distinguish species are cardinal growth temperature, growth rate, morphological (growth) characteristics in culture, and mating behavior. Due to intraspecific variation and overlapping characters, accurate identification of isolates is often difficult, even for specialists. Moreover, some species (e.g., P. megasperma, $P$. cryptogea) probably consist of species complexes rather than single taxa.

Interspecific hybridization in the genus Phytophthora has not been investigated intensively. Brasier (4) suggested the potential for zoospore fusion to produce hybrids. A few attempts to create hybrids in the laboratory were performed successfully $(1,2,11,15)$. Proof of hybridization was also obtained by DNA analysis $(11,12,15)$. Natural hybridization has never been proven but may have occurred with $P$. meadii (24). Due to their atypical morphology, natural hybrids of Phytophthora are difficult to detect by classical taxonomy and, hence, their existence has been hypothetical for a long time. Recently, however, molecular analysis of

Corresponding author: P. J. M. Bonants;

E-mail address: p.j.m.bonants@ @lant.wag-ur.nl

Publication no. P-2000-0606-01R

(C) 2000 The American Phytopathological Society certain atypical isolates found in hydroponic systems in the Netherlands revealed that these isolates actually represent hybrids of $P$. nicotianae and $P$. cactorum (21). The hybrid nature of the isolates involved, isolated from Spathiphyllum and Primula spp., was confirmed using isozymes, random amplified polymorphic DNAs and Southern analyses. Brasier et al. (8) studied an unusual Phytophthora species from an Alnus sp. that also might be a hybrid, possibly involving $P$. cambivora as one parent. Based on chromosome karyotyping, internal transcribed spacer (ITS) sequence data, and amplified fragment length polymorphisms (AFLP) fingerprinting, Brasier et al. (5) concluded that these isolates represent a heterogeneous population of polyploid hybrids between a $P$. cambivora-like species and an unknown species related to $P$. fragariae.

In the present study a number of new atypical Phytophthora isolates from various host species (Lavandula, Lewisia, and Cyclamen spp.) was characterized culturally and morphologically, as well as by isozyme analysis, analysis of the ITS region of the ribosomal DNA gene repeat (rDNA), and AFLP polymorphisms (27) to confirm the hybrid status of the isolates. The hypothesis of whether different hybridization events took place or whether the hybrid isolates belong to a single clonal lineage was tested with AFLP analysis. Two atypical isolates from Idesia and Rhododendron spp. that morphologically resemble $P$. cactorum were included as well.

\section{MATERIALS AND METHODS}

Sources and cultivation of isolates. Fungal isolates used in this study and some of their characteristics are listed in Table 1. Isolates PD 93/1339 and PD 94/1166 were inoculated on a Spatiphyllum sp., and several reisolates from the plants were recovered. Isolates of all Phytophthora spp. were grown in $50 \mathrm{ml}$ of V8 juice medium: $125 \mathrm{ml}$ of V8, and $11.5 \mathrm{~g}$ of oatmeal were 
added to $500 \mathrm{ml}$ of demineralized water, boiled for $5 \mathrm{~min}$, and clarified by centrifugation $(15 \mathrm{~min}$ at $1600 \mathrm{rpm}) . \mathrm{CaCO}_{3}(0.94 \mathrm{~g})$ was added to solution and demineralized water was added to a final volume of $625 \mathrm{ml}$. The mixture was autoclaved for $30 \mathrm{~min}$ at $110^{\circ} \mathrm{C}$. After incubation at $22^{\circ} \mathrm{C}$ for 15 to 30 days, mycelium was harvested by filtration, washed with demineralized water, freezedried, and stored at $-20^{\circ} \mathrm{C}$ until DNA isolation.

Biochemical, morphological, and cultural characteristics. Biochemical (isozyme analysis [MDHP and $\mathrm{MDH}]$ ), morphological (dimensions of oogonia, oospores, and sporangia), and cultural (maximum growing temperature) characteristics were determined as described before (21).

Molecular techniques. DNA isolation. Freeze-dried mycelium (10 to $50 \mathrm{mg}$ ) was ground in microcentrifuge tubes with sterile sand and a pestle. DNA was isolated with the Puregene kit (Gentra/Biozym, Landgraaf, the Netherlands) according to the manufacturer's instructions.

ITS-PCR. ITS-PCR was performed with primers I1 and I4 (18) as previously described (3). PCR product (10 $\mu \mathrm{l})$ was digested for $3 \mathrm{~h}$ at $37^{\circ} \mathrm{C}$ with the restriction enzymes $A l u \mathrm{I}, T a q \mathrm{I}, M s p \mathrm{I}$, and HaeIII according to the manufacturer's instructions (Boerhringer $\mathrm{GmbH}$, Mannheim, Germany). After digestion, products were separated on $2.5 \%$ agarose gels in $0.5 \times \mathrm{TBE}$ buffer $(10 \times \mathrm{TBE}=$ $0.9 \mathrm{M}$ Tris- $\mathrm{HCl}$ [pH 8.0], 0.9 M Boric acid, $10 \mathrm{mM}$ EDTA). Bands were visualized by ethidium bromide staining and UV illumination. Sizes of fragments were calculated using a 100-bp ladder (Boehringer) as the molecular weight standard. ITS-PCR products were cloned into a pGEM-T vector (Promega, Leiden, the Netherlands). Transformation was performed in JM109 competent cells (Promega). Plasmid DNA was isolated with Quiagen columns (Quiagen, Breda, the Netherlands). Sequence analysis was performed on an ABI3700 automatic sequencer (PerkinElmer, Nieuwerkerk a/d IJssel, the Netherlands). Some additional sequences from $P$. cactorum and $P$. nicotianae were described by Cooke and Duncan (9) and Crawford et al. (10). Primers for $P$. cactorum and $P$. nicotianae were developed based on consensus sequences.

Specific PCR conditions were: buffer (10 mM Tris/HCl, $\mathrm{pH} 8.3$ ), $50 \mathrm{mM} \mathrm{KCl}, 1.5 \mathrm{mM} \mathrm{MgCl} 2,60 \mu \mathrm{M} \mathrm{dNTP}, 0.6 \mu \mathrm{M}$ each primer, 1 unit of Taq-polymerase (Boehringer) and $10 \mathrm{ng}$ of fungal DNA in a final reaction volume of $25 \mu \mathrm{l}$. Reactions were performed in a PTC200 thermocycler (MJ Research/Biozym, Landgraaf, the Netherlands). The PCR profile was $2 \mathrm{~min}$ at $94^{\circ} \mathrm{C}$ for 35 cycles $\left(\right.$ cycle $=30 \mathrm{~s}$ at $94^{\circ} \mathrm{C}, 30 \mathrm{~s}$ at $57^{\circ} \mathrm{C}, 60 \mathrm{~s}$ at $72^{\circ} \mathrm{C}$ ), a final extension of $10 \mathrm{~min}$ at $72^{\circ} \mathrm{C}$, and cooling to $4^{\circ} \mathrm{C}$. PCR amplicons were separated on $1.0 \%$ agarose gels and visualized as described above.

Radioactive AFLP. Two-hundred and fifty nanograms DNA was digested with EcoRI (10 U) and Mse $1(10 \mathrm{U})$ for $4 \mathrm{~h}$ at $37^{\circ} \mathrm{C}$ in RL buffer (5 mM Tris/HCl [pH 7.5], $5 \mathrm{mM} \mathrm{MgAc,} 25 \mathrm{mM} \mathrm{KAc}$, $2.5 \mathrm{mM}$ DTT, BSA at $25 \mathrm{ng} / \mu \mathrm{l})$. Digestion was confirmed on agarose gels. Adapters (Table 2) were ligated to restriction fragments. Final concentrations were $2.5 \mathrm{U}$ of ligase (Amersham Pharmacia Biotech, Roosendaal, the Netherlands), $0.1 \mu \mathrm{M} \mathrm{EcoRI}$ adapter, $1.0 \mu \mathrm{M}$ MseI adapter and $0.2 \mu \mathrm{M}$ ATP. Ligation was performed overnight at 10 to $12^{\circ} \mathrm{C}$. Ligation products were diluted 10 times with ultrapure water. Nonselective amplification was performed with 0-primers (Table 2) to amplify all restriction fragments. PCR conditions were as follows: buffer $(10 \mathrm{mM}$ Tris/ $\mathrm{HCl}, \mathrm{pH} 8.3), 50 \mathrm{mM} \mathrm{KCl}, 1.5 \mathrm{mM} \mathrm{MgCl}_{2}, 60 \mu \mathrm{M}$ dNTP, $5 \mathrm{ng} / \mu \mathrm{l}$ of each primer, $1 \mathrm{U}$ of Taq-polymerase (Boehringer) and $5 \mu \mathrm{l}$ of diluted ligation product in a final reaction volume of $25 \mu \mathrm{l}$. Reactions were performed in a PTC200 thermocycler (MJ Research/Biozym). The PCR profile was $2 \mathrm{~min}$ at $94^{\circ} \mathrm{C}$ for 35 cycles $\left(\right.$ cycle $=30 \mathrm{~s}$ at $94^{\circ} \mathrm{C}, 30 \mathrm{~s}$ at $56^{\circ} \mathrm{C}, 90 \mathrm{~s}$ at $72^{\circ} \mathrm{C}$ ), a final extension of $10 \mathrm{~min}$ at $72^{\circ} \mathrm{C}$, and cooling to $4^{\circ} \mathrm{C}$. After nonselective amplification, products were separated on $1.0 \%$ agarose gels. Bands were visualized by ethidium bromide staining and UV illumination. Products were diluted 20 times in ultrapure water and stored at $-20^{\circ} \mathrm{C}$ until selective amplification. Selective PCR conditions were as described above, except with $200 \mu \mathrm{M}$ dNTP, $5 \mathrm{ng}$ of radioactively labeled EcoRI primer, $30 \mathrm{ng}$ of $M s e 1$ primer, and $5 \mu \mathrm{l}$ of diluted (1:20) nonselective amplification product in a final reaction volume of $20 \mu \mathrm{l}$. EcoRI primer was radioactively labeled with ${ }^{33} \mathrm{P}$-ATP using kinase (Amersham). AFLP reactions were performed in a PE 9600 thermocycler (Perkin Elmer). The cycling profile was $2 \mathrm{~min}$ at $94^{\circ} \mathrm{C}$ for 13 cycles $\left(\right.$ cycle $=30 \mathrm{~s}$ at $94^{\circ} \mathrm{C}, 30 \mathrm{~s}$ at $65^{\circ} \mathrm{C}, 60 \mathrm{~s}$ at $72^{\circ} \mathrm{C}$; annealing temperature was lowered $0.7^{\circ} \mathrm{C}$ each cycle), followed by 23 cycles (of $30 \mathrm{~s}$ at $94^{\circ} \mathrm{C}, 30 \mathrm{~s}$ at $56^{\circ} \mathrm{C}, 60 \mathrm{~s}$ at $72^{\circ} \mathrm{C}$ ), a final extension of

TABLE 1. Collection data and summary information about the isolates of Phytophthora used in this study

\begin{tabular}{|c|c|c|c|c|c|c|c|}
\hline \multirow{2}{*}{$\begin{array}{l}\text { Species } \\
\text { Isolate number }\end{array}$} & \multirow[b]{2}{*}{ Host plant } & \multirow[b]{2}{*}{ Location } & \multicolumn{2}{|c|}{ Isozyme genotype } & \multirow[b]{2}{*}{ Sexual type } & \multirow{2}{*}{$\begin{array}{l}\text { Amphigynous } \\
\text { antheridia } \%\end{array}$} & \multirow{2}{*}{$\begin{array}{l}\text { Maximum growth } \\
\text { temperature }\left({ }^{\circ} \mathrm{C}\right)\end{array}$} \\
\hline & & & MDHP & $\mathrm{MDH}$ & & & \\
\hline \multicolumn{8}{|c|}{ Phytophthora cactorum } \\
\hline P6183 & Rubus idaeus & New York & $92 / 92$ & $93 / 93$ & Homothallic & 0 & $30-32$ \\
\hline P1943 & Panax quinquefolius & Wisconsin & $92 / 92$ & $93 / 93$ & Homothallic & 0 & $30-32$ \\
\hline P6187 & Fragariae $\times$ ananassa & New York & $92 / 92$ & $93 / 93$ & Homothallic & 0 & $30-32$ \\
\hline \multicolumn{8}{|l|}{ P. nicotianae } \\
\hline P582 & Nicotiana tabacum & Kentucky & $100 / 100$ & $100 / 100$ & Heterothallic & 100 & $35-36.5$ \\
\hline P1753 & Nicotiana tabacum & Australia & $100 / 100$ & $100 / 100$ & Heterothallic & 100 & $35-36.5$ \\
\hline P1923 & Vanilla planifolia & French Polynesia & $100 / 100$ & $100 / 100$ & Heterothallic & 100 & $35-36.5$ \\
\hline \multicolumn{8}{|l|}{ P. cf. cactorum } \\
\hline PD $95 / 5111$ & Idesia & Noord-Brabant ${ }^{\mathrm{a}}$ & $92 / 100$ & $93 / 93$ & Homothallic & $10-20$ & $30-32$ \\
\hline PD 92/229 & Rhododendron & Gelderland $^{\mathrm{a}}$ & $92 / 100$ & $93 / 93$ & Homothallic & 0 & $30-32$ \\
\hline \multicolumn{8}{|c|}{$P$. nicotianae $\times P$. cactorum } \\
\hline PD 93/1339 & Spathiphyllum sp. & Zuid-Holland ${ }^{\mathrm{a}}$ & $92 / 100$ & $93 / 100$ & Homothallic & $80-90$ & $35-36.5$ \\
\hline PD 94/1166 & Spathiphyllum sp. & Zuid-Holland & $92 / 100$ & $93 / 100$ & Homothallic & $80-90$ & $35-36.5$ \\
\hline PD 98/8734 & Spathiphyllum sp. & Groningen $^{\mathrm{a}}$ & $92 / 100$ & $93 / 100$ & Homothallic & $80-90$ & $35-36.5$ \\
\hline PD 94/988 & Primula & Gelderland & $92 / 100$ & $93 / 100$ & Homothallic & $80-90$ & $35-36.5$ \\
\hline PD 97/8771 & Lavandula & Noord-Holland $^{\mathrm{a}}$ & $92 / 100$ & $93 / 100$ & Homothallic & $80-90$ & $35-36.5$ \\
\hline PD $97 / 9389$ & Lavandula & Noord-Brabant & $92 / 100$ & $93 / 100$ & Homothallic & $80-90$ & $35-36.5$ \\
\hline PD $98 / 9165$ & Lavandula & Noord-Brabant & $92 / 100$ & $93 / 100$ & Homothallic & $80-90$ & $35-36.5$ \\
\hline PD 98/9105 & Lewisia & Noord-Holland & $92 / 100$ & $93 / 100$ & Homothallic & $80-90$ & $35-36.5$ \\
\hline PD 97/10235 & Cyclamen & Noord-Holland & $92 / 100$ & $93 / 100$ & Homothallic & $80-90$ & $35-36.5$ \\
\hline PD 99/1760 & Cyclamen & Noord-Brabant & $92 / 100$ & $93 / 100$ & Homothallic & $80-90$ & $35-36.5$ \\
\hline PD AN 99/3 & Cyclamen & Noord-Holland & $92 / 100$ & $93 / 100$ & Homothallic & $80-90$ & $35-36.5$ \\
\hline
\end{tabular}

\footnotetext{
${ }^{\mathrm{a}}$ The Netherlands.
} 
$10 \mathrm{~min}$ at $72^{\circ} \mathrm{C}$, and cooling to $4^{\circ} \mathrm{C}$. Selective amplification products were diluted with an equal volume of formamide dye (98\% formamide, $10 \mathrm{mM}$ EDTA, 0.1\% brome-phenolblue, and $0.1 \%$ xylenecyanol), heated for $5 \mathrm{~min}$ at $95^{\circ} \mathrm{C}$ to denature, and immediately put on ice. Between 3 and $5 \mu l$ of the diluted product was loaded on a $6 \%$ denaturing polyacrylamide gel (20:1 acrylamide/bis, 7.5 M urea, 0.5× TBE buffer) or Sequagel (Biozym). Pre-electrophoresis with constant power $( \pm 75 \mathrm{~W})$ for $20 \mathrm{~min}$ until the temperature was $50^{\circ} \mathrm{C}$ and electrophoresis at constant power (constant temperature was $50^{\circ} \mathrm{C}$ ) was performed on a sequencing system (Gibco BRL, Breda, the Netherlands) until the dye was approximately $12 \mathrm{~cm}$ above the bottom of the gel. Gels were dried on Whatman-3MM paper (Whatman Inc., Clifton, $\mathrm{NJ}$ ) covered with plastic wrap in a vacuum geldryer (Biorad, Veenendaal, the Netherlands). Dried gels were exposed to X-ray films (X-OMAT, Kodak, Odijk, the Netherlands) for 1 to 3 days.

Hybridization. Specific AFLP bands for $P$. cactorum and $P$. nicotianae were excised by positioning the autoradiogram carefully above the dried gel. Radioactive ink was used for correct positioning. Products were eluted from Whatman paper (Whatman Inc.) pieces by boiling in $50 \mu \mathrm{l}$ of ultrapure water in microcentrifuge tubes. The boiling solution was separated from Whatman paper (Whatman Inc.) by centrifugation and stored in clean tubes at $-20^{\circ} \mathrm{C}$. Specific bands were reamplified using the 0 primers as described above. Reamplified specific bands were radioactively labeled $\left({ }^{32} \mathrm{P}\right)$ by random-prime labeling (Boehringer) and hybridized with Southern blots of genomic DNA digested with EcoRI as described before (21).

Fluorescent AFLP. Protocols for fluorescent AFLP analysis were the same as for radioactive AFLP, except for the incorporation of Cy5-labeled fluorescent primers (Amersham) in the selective amplification reaction. Samples were analyzed on Sequagel (Biozym) or Readymix (Amersham) polyacrylamide gels and run on an ALFexpress automatic sequencer (Amersham). Conditions were $1500 \mathrm{~V}, 60 \mathrm{~mA}, 35 \mathrm{~W}$, and $55^{\circ} \mathrm{C}$. Running buffer was $0.6 \times$ TBE. A fluorescently labeled 50-bp ladder (Amersham) was used as a molecular weight standard.

Data analysis. AFLP patterns were analyzed with ImageMaster software (Amersham). Presence or absence of the reproducible bands was converted in binary data and incorporated in the analysis. A similarity matrix was constructed using the method of Nei and Li (22). Unweighted pair group method cluster analysis of binary data was performed with Treecon software (26) and a dendrogram was constructed with a distance scale.

TABLE 2. DNA sequences of internal transcribed spacer (ITS) primers, amplified fragment length polymorphism (AFLP) primers, and AFLP adapters used in this study

\begin{tabular}{ll}
\hline Primer/Adapter & Sequence \\
\hline ITS & \\
I1 & 5'-TCCGTAGGTGAACCTGCGG \\
I4 & 5'-TCCTCCGCTTATTGATATGC \\
CACTF1 & 5'-GGTGAGCCCTATCATGGC \\
CACTR1 & 5'-AGTCGGTCCGAAAACCAGC \\
NICF1 & 5'-AGTGAGCCCTATCAAAAAAAAG \\
NICR2.1 & 5'-GCATACCGAAGTACACATTAAGTT \\
AFLP & \\
E00 & 5'-GACTGCGTACCAATTC \\
M00 & 5'-GATGAGTCCTGAGTAA \\
E20 & 5'-GACTGCGTACCAATTCGC \\
E21 & 5'-GACTGCGTACCAATTCGG \\
M16 & 5'-GATGAGTCCTGAGTAACC \\
AFLP adapters: & \\
EcoRI & 5'-CTCGTAGACTGCGTACC \\
MseI & CATCTGACGCATGGTTAA-5' \\
& 5'-GACGATGAGTCCTGAG \\
\end{tabular}

\section{RESULTS}

Biochemical, morphological, and cultural characteristics. Putative hybrid isolates were identified by their heterodimeric isozyme patterns using MDHP (malic enzyme) and MDH (malate dehydrogenase) (Table 1). These isolates were homothallic, had 80 to $90 \%$ amphigynous antheridia, and a high cardinal growth temperature $\left(\approx 36^{\circ} \mathrm{C}\right)$. Two isolates from Rhododendron and Idesia spp. (PD 92/229 and PD 95/5111, respectively) were atypical in their isozyme patterns, which resembled the hybrids for only one of the enzymes (Table 1). They had a three-banded, heterodimeric, pattern with MDHP, similar to that of the putative hybrids, but the typical $P$. cactorum band with MDH (Table 1). These isolates were also homothallic but had largely paragynous antheridia, a lower cardinal growth temperature $\left(30.5^{\circ} \mathrm{C}\right)$, and are presently classified as Phytophthora cf. cactorum because of their morphological resemblance to this species.

ITS-RFLP. The PCR amplification products of the $P$. cactorum isolates with primers I1 and I4 (880 bp) were slightly smaller than those of the P. nicotianae isolates (900 bp) (data not shown). This agreed with the total sequence of the I1/I4 PCR fragment (882 and $892 \mathrm{bp}$ for $P$. cactorum and $P$. nicotianae, respectively). After digestion of the I1/I4 PCR product with AluI (Fig. 1) a clear difference emerged between $P$. cactorum (lanes 2 through 4 ) and $P$. nicotianae (lanes 12 through 14) isolates. For TaqI and HaeIII, the differences were only due to small length differences (data not shown). For MspI (data not shown) and Alu1 (Fig. 1), the differences were due to restriction site changes. All $P$. nicotianae $\times P$. cactorum hybrid isolates contained restriction fragments from both parental Phytophthora species. However, differences between hybrid isolates were also observed (Fig. 1). Isolate PD 94/988 (lane 7) gave a weak $P$. cactorum pattern and a strong $P$. nicotianae pattern compared with the other hybrid isolates. The

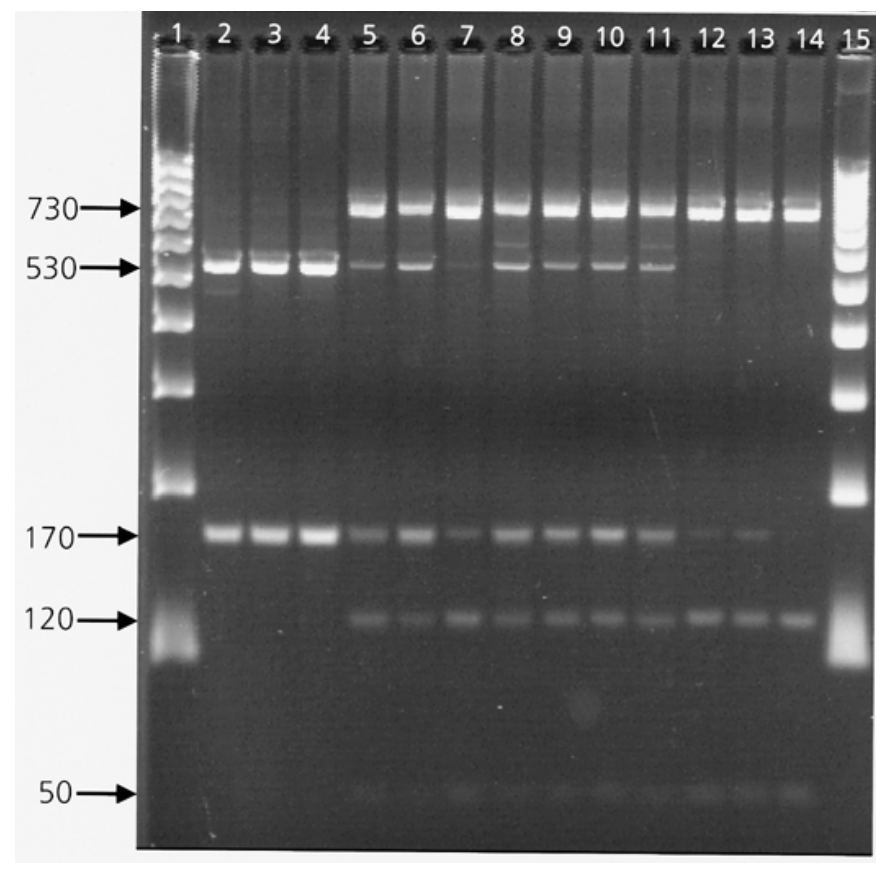

Fig. 1. Gel electrophoresis of polymerase chain reaction product with primers I1/I4 (Table 2) of DNA from several isolates of Phytophthora species digested with $A l u \mathrm{I}$ (lanes 2 through 14). Lanes 1 and 15: molecular weight markers (100-bp intervals); lanes 2 through 14: $P$. cactorum P6183, $P$. cactorum $\mathrm{P} 1943, P$. cactorum $\mathrm{P} 6187, P$. nicotianae $\times P$. cactorum $\mathrm{PD}$ 93/1339, $P$. nicotianae $\times P$. cactorum $\mathrm{PD}$ 93/1339 MZ, $P$. nicotianae $\times P$. cactorum $\mathrm{PD}$ 94/988, $P$. nicotianae $\times P$. cactorum $\mathrm{PD} 94 / 1166, P$. nicotianae $\times$ P. cactorum PD 97/10235, P. nicotianae $\times$ P. cactorum $\mathrm{PD} 97 / 8771, P$. nicotianae $\times P$. cactorum PD 97/9389, P. nicotianae P582, P. nicotianae P1753, and P. nicotianae P1923, respectively. MZ: monozoospore culture. 
ITS RFLP data for the Phytophthora cf. cactorum isolates were identical to $P$. cactorum (data not shown).

Specific PCR. Sequences of the I1/I4 PCR product of several $P$. cactorum and $P$. nicotianae isolates were determined or derived from databases; the consensus sequence was determined. Primers either specific for $P$. cactorum or for $P$. nicotianae were designed on the basis of sequence differences and are listed in Table 2. PCR reactions were performed with these primers using DNAs from several isolates. When using $P$. cactorum primers only, the $P$. cactorum isolates and the $P$. nicotianae $\times P$. cactorum hybrid isolates showed a PCR product of the expected size (data not shown). The same was true when using the $P$. nicotianae primers. IN a multiplex PCR experiment (Fig. 2) using two $P$. cactorum and two $P$. nicotianae primers (Table 2), P. cactorum isolates (lanes 2 and 5) gave a small $(370 \mathrm{bp})$ product (marked C), $P$. nicotianae isolates (lanes 3 and 6) gave a large $(700 \mathrm{bp})$ product (marked $\mathrm{N}$ ) and the $P$. nicotianae $\times P$. cactorum hybrid isolates (lanes 4 and 7) amplified both products, proving that those isolates contained ITS sequences from both Phytophthora species. All $P$. nicotianae $\times P$. cactorum hybrid isolates were screened with this multiplex PCR and all resulted in mixed patterns. The Phytophthora cf. cactorum isolates only showed the P. cactorum band (data not shown).

Radioactive AFLP. DNA from 14 isolates was subjected to radioactive AFLP analysis. The primer combination E21 $\times \mathrm{M} 16$ revealed bands specific for either $P$. cactorum or $P$. nicotianae (Fig. 3). These bands were also present in the putative hybrids (Fig. 3); the AFLP profiles of the $P$. nicotianae $\times P$. cactorum hybrid isolates are the sum of the bands of $P$. cactorum and $P$. nicotianae. This was not due to mixed cultures: the AFLP pattern of isolate PD 93/1339 (lane 11) was identical to that of a monozoospore isolate of PD 93/1339 (lane 12). Some differences

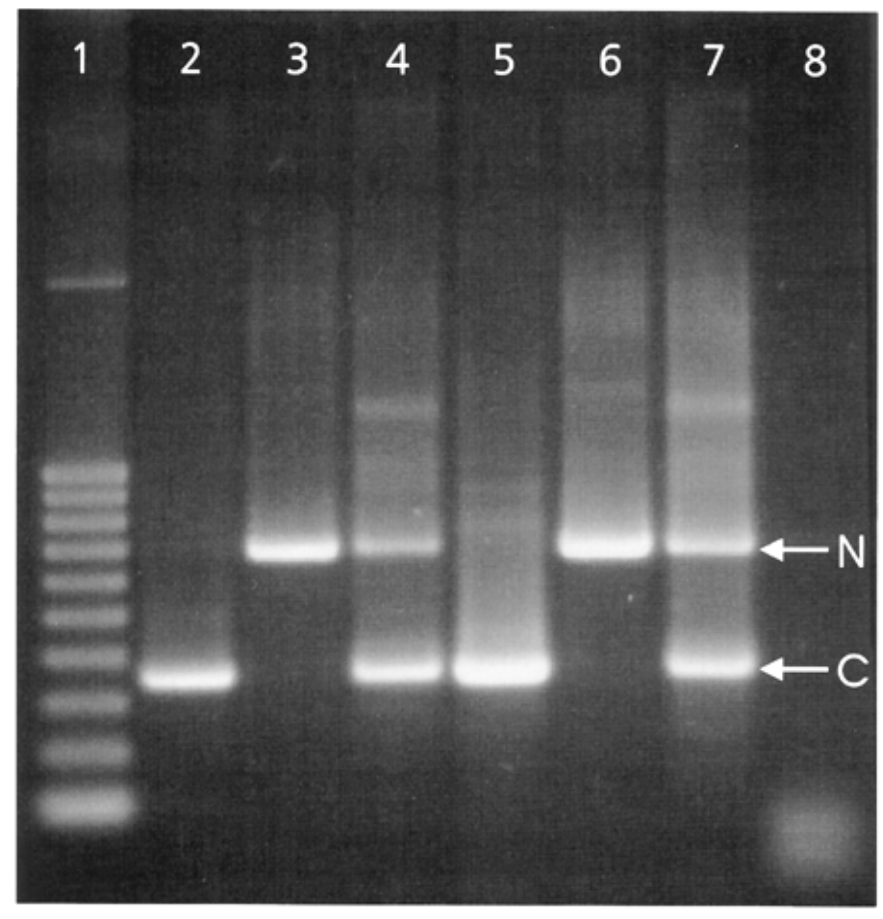

Fig. 2. Gel electrophoresis of multiplex polymerase chain reaction products with primers for Phytophthora cactorum (CACTF1 and CACTR1 [Table 2]) and for P. nicotianae (NICF1 and NICR2.1 [Table 2]) from the DNA of several Phytophthora isolates. Lane 1: molecular weight markers (100-bp intervals); lanes 2 through 7: P. cactorum P1943; P. nicotianae P582; $P$. nicotianae $\times P$. cactorum PD 94/1166; $P$. cactorum P6183; $P$. nicotianae P1753; and $P$. nicotianae $\times P$. cactorum PD 93/1339, respectively; lane 8 : ultrapure water. PCR products specific for P. nicotianae and $P$. cactorum are designated with $\mathrm{N}$ and $\mathrm{C}$ respectively. between the different hybrid isolates were observed. The patterns of isolates PD 93/1339 (lane 11) and PD 94/1166 (lane 14), both isolated from a Spathiphyllum sp., were almost identical, whereas the pattern of PD 94/988 (lane 13), isolated from a Primula sp., differed significantly. The AFLP patterns of Phytophthora cf. cactorum isolates (lanes 7 through 10) were comparable to $P$.

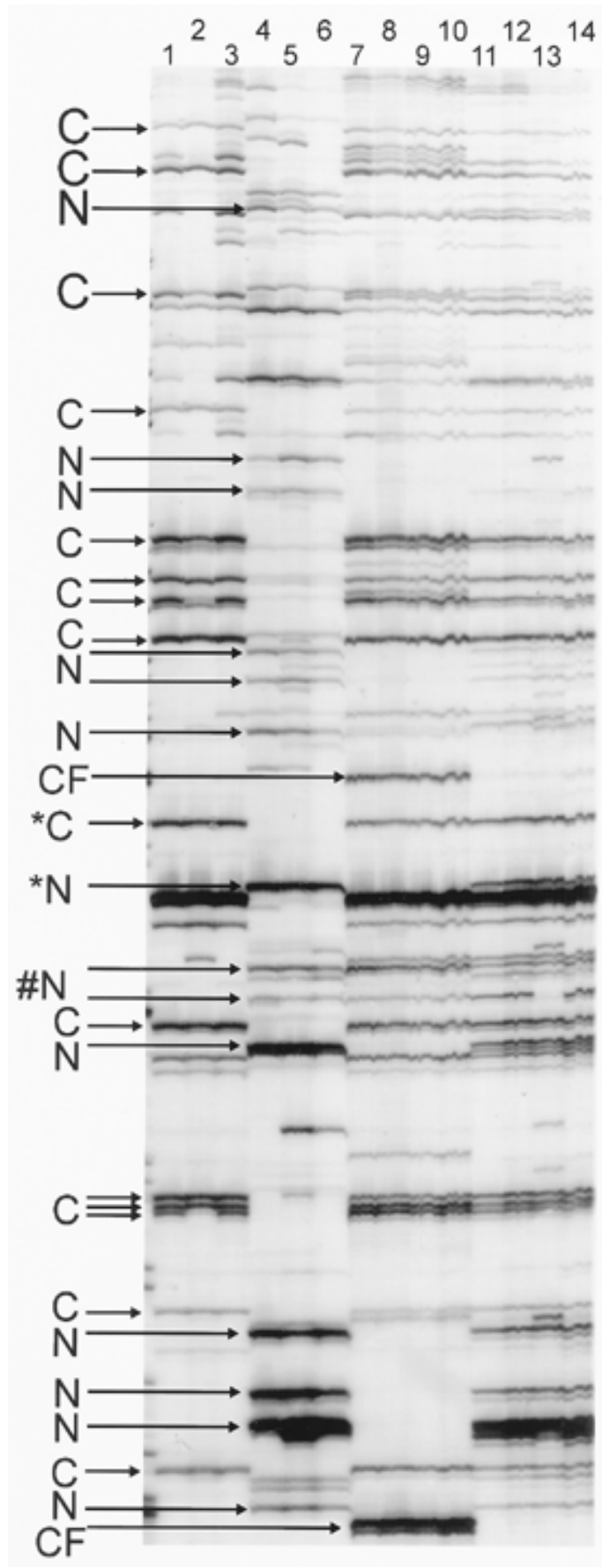

Fig. 3. Radioactive amplified fragment length polymorphic (AFLP) DNA fingerprint patterns of several Phytophthora isolates with primer combination E21 $\times$ M16. Lanes 1 through 3: P. cactorum isolates P6183, P1943, and P6187, respectively; lanes 4 through 6: P. nicotianae isolates P582, P1753, and P1923, respectively; lanes 7 through 10: Phytophthora cf. cactorum isolates PD 95/511, PD 92/229 PC-vanc, PD 92/229 PC, and PD 92/229 MZ, respectively; lanes 11 through 14: $P$. nicotianae $\times P$. cactorum isolates $\mathrm{PD}$ 93/1339 PC, PD 93/1339 MZ, PD 94/988, and PD 94/1166, respectively. PCvanc: parent culture grown on vancomycine; PC: parent culture; MZ: monozoospore culture. Arrows indicate P. cactorum (C)-, P. nicotianae (N)or $P$. cf. cactorum (CF)-specific AFLP fragments and $P$. nicotianae bands present in $P$. cf. cactorum isolates $(\# \mathrm{~N})$. ${ }^{*} \mathrm{C}$ and $* \mathrm{~N}$ indicate AFLP bands selected for Southern hybridization experiments. 
cactorum, although they also contained a small number of bands comigrating with $P$. nicotianae bands (marked with \#N) and some unique AFLP bands (marked CF).

Cluster analysis of 100 reproducible AFLP bands showed that isolates of $P$. nicotianae $\times P$. cactorum were grouped between both parental species (Fig. 4). Isolates of Phytophthora cf. cactorum grouped between the hybrids and $P$. cactorum. The different clustering of isolate PD 94/988 is clearly shown. Other primer combinations showed the same results (data not shown).

Hybridization. A P . cactorum-specific AFLP fragment (Fig. 3, *C) was excised from the radioactive AFLP gel and used in Southern analysis (Fig. 5). Results showed several RFLP bands in the $P$. cactorum isolate (lane 1) that were also present in the $P$. nicotianae $\times P$. cactorum hybrid isolate (lane 4 ). The same was true for the RFLP band present in the $P$. nicotianae isolate (lane 2). The Phytophthora cf. cactorum isolate (lane 3) only showed the $P$. cactorum RFLP bands. Hybridization with a $P$. nicotianaespecific AFLP fragment (Fig. 3, *N) showed a similar pattern (data not shown).

Fluorescent AFLP. Similar results were obtained using fluorescent AFLP analysis on 17 isolates (Fig. 6). Again, the $P$. nicotianae $\times P$. cactorum isolates showed bands specific for $P$. cactorum and $P$. nicotianae. Eight new Phytophthora isolates (PD 97/10235, PD 97/8771, PD 97/9389, PD 98/8734, PD 98/9165, PD 98/9105, PD 99/1760, and PD AN 99/3) were discovered and were hybrid by nature (Fig. 6), with $P$. nicotianae and $P$. cactorum as parental species. They were isolated from new hosts (Lavendula, Cyclamen, and Lewisia spp.).

Cluster analysis of 350 reproducible AFLP bands from 2 primer combinations $(\mathrm{E} 21 \times \mathrm{M} 16$ and E20 $\times \mathrm{M} 16)$ showed that the $P$. nicotianae $\times P$. cactorum hybrid isolates again grouped between the two parental Phytophthora species (Fig. 7). Other primer combinations gave similar results (data not shown). There was some variation among the hybrid isolates. Isolates PD 98/9165 and PD 94/988 differed from the other hybrid isolates. Isolates PD 93/1339 and PD 98/8734, both from a Spathiphyllum sp., clustered together, although they were isolated from plants from different regions in the Netherlands. The same was true for the Lavandula sp. isolates PD 97/8771 and PD 97/9389, and for the Cyclamen sp. isolates PD 97/10235 and PD 99/1760. Spathiphyllum sp. isolate PD 94/1166 clustered between the other hybrid isolates, although it clustered together with the other Spathiphyllum sp. isolates in the radioactive analysis (Fig. 4). Reisolations made from inoculated Spathiphyllum sp. plants showed exactly the same AFLP pattern as the inoculated isolate (data not shown).

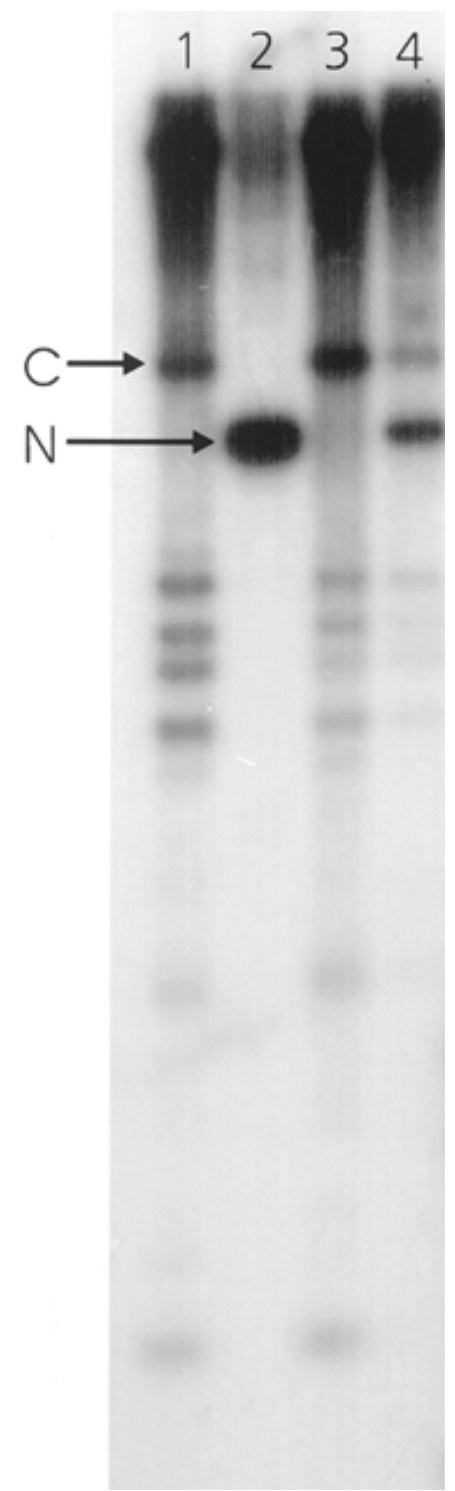

Fig. 5. Southern blot from Phytophthora DNA digested with EcoRI and hybridized with amplified fragment length polymorphism band $* \mathrm{C}$ (Fig. 3). Lane 1: P. cactorum P6183; lane 2: P. nicotianae P1753; lane 3: P. cf. cactorum PD 92/229; lane 4: P. nicotianae $\times$ P. cactorum $\mathrm{PD}$ 93/1339. C and $\mathrm{N}$ indicate $P$. cactorum- and $P$. nicotianae-specific restriction fragment length polymorphism bands, respectively.

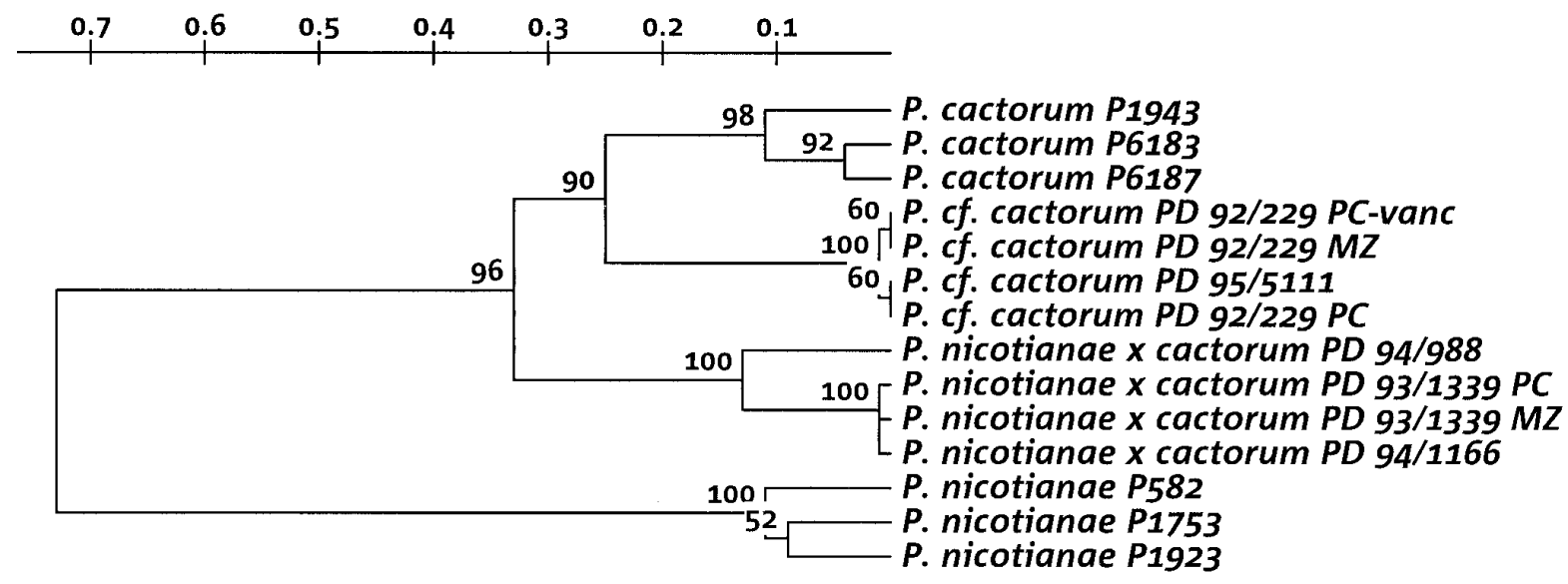

Fig. 4. Unweighted pair group method cluster analysis of binary data dendrogram constructed from 100 bands of amplified fragment length polymorphism fingerprint patterns of Phytophthora isolates with primer combination E21×M16, as shown in Figure 3. Distance scale (in fixed mutations per site) is drawn. Bootstrap values of 1,000 replications are shown in percentages above branches. 


\section{DISCUSSION}

Little is known about interspecific hybridization in the genus Phytophthora. If exchange of genetic material occurs in the hybrid oospores, interspecific crosses may be an important source of variability. Demonstration of interspecific hybridization in the laboratory is difficult due to the very low percentage of germination of hybrid oospores (15).

The occurrence of natural $P$. nicotianae $\times P$. cactorum hybrids was recently demonstrated by isozyme analysis, RAPD profiling, and hybridization of Southern blots with species-specific RAPD bands (21) on three isolates. The current molecular analysis (ITSRFLP, ITS-PCR, and AFLP) provide additional evidence for the hybrid nature of these and more atypical Phytophthora isolates. In the course of several years, a total of 13 hybrid isolates have been detected associated with disease symptoms on 5 hosts (Spathiphyllum, Primula, Lavandula, Cyclamen, and Lewisia spp.). Apparently, hybrids are not extremely rare in greenhouses in the Netherlands, where hydroponic systems and diseases caused by Phytophthora are common in ornamental cultures.

The two atypical Phytophthora isolates (Phytophthora cf. cactorum PD 92/229 and PD 95/5111) need not be hybrids between $P$.

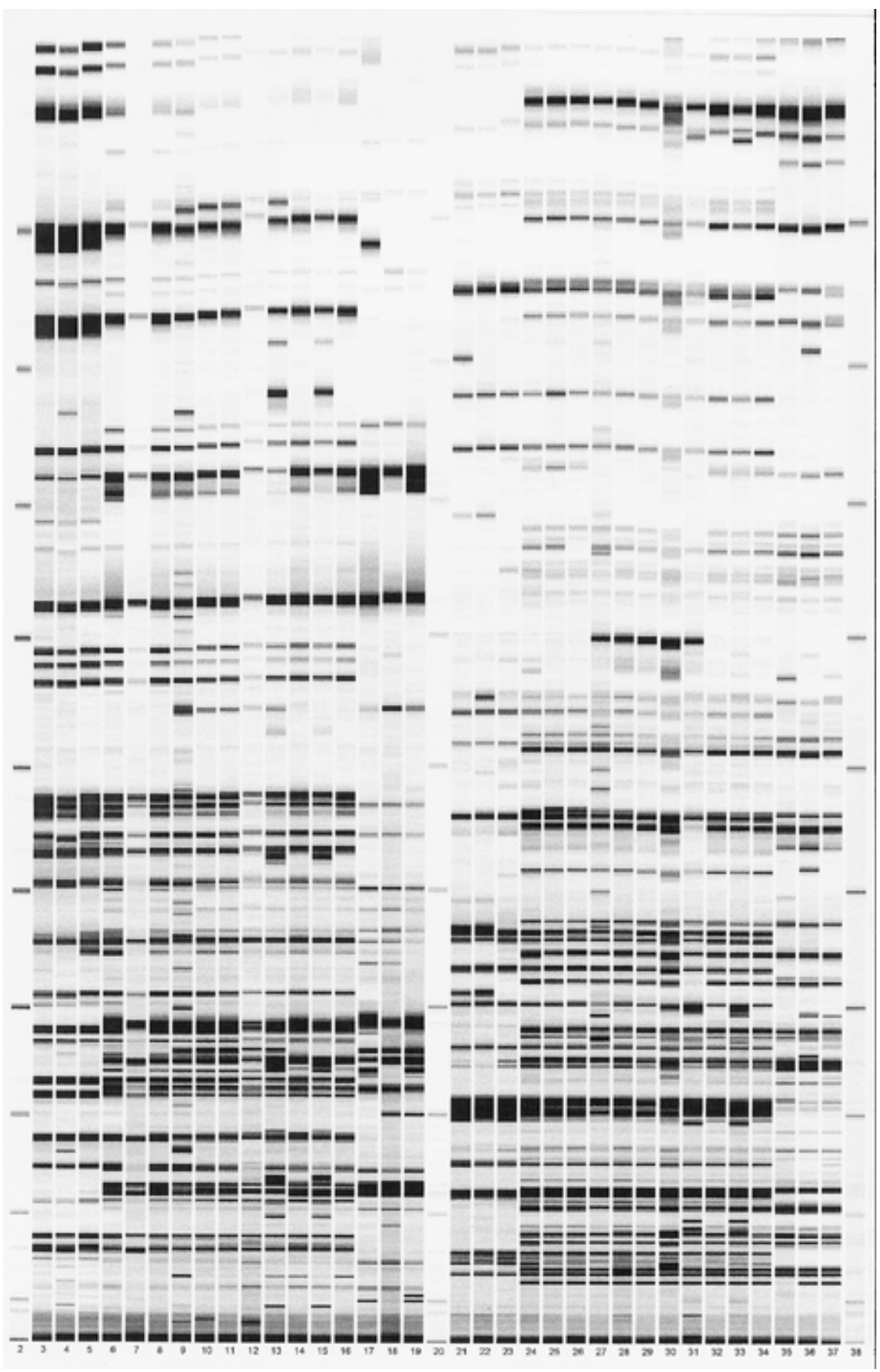

Fig. 6. Fluorescent amplified fragment length polymorphism DNA fingerprint patterns of several Phytophthora isolates with primer combinations E21xM16 (lanes 3 through 19) and E20×M16 (lanes 21 through 37). Lanes 2, 20, and 38: 50-bp marker; lanes 3 through 5 and 21 through 23: P. cactorum P6183, P1943, and P6187, respectively; lanes 6 through 16 and 24 through 34: P. nicotianae $\times$ P. cactorum PD 93/1339, PD 94/1166, PD 98/8734, PD 94/988, PD 97/8771, PD 97/9389, PD 98/9165, PD 98/9105, PD 97/10235, PD AN 99/3, and PD 98/1760, respectively; lanes 17 through 19 and 35 through 37: P. nicotianae P582, P1753, and P1923, respectively. 
cactorum and $P$. nicotianae. Analyses of the mtDNA of these two isolates with two restriction enzymes (HindII and ScrfI) generated a unique banding pattern, different from both $P$. nicotianae and $P$. cactorum and from the $P$. nicotianae $\times P$. cactorum hybrid isolates $(20,21)$. The possibility, however, that a third parental species, in addition to $P$. nicotianae and $P$. cactorum, was involved has not been ruled out. The deviating mtDNA haplotype may be explained in other ways. Several haplotypes of mtDNA may exist in $P$. cactorum, as in $P$. nicotianae (17), and it was reported previously that $P$. cactorum was not a homogeneous species $(19,23)$. The two Phytophthora cf. cactorum isolates, thus, could represent an evolutionary lineage within $P$. cactorum with a different isozyme pattern for MDHP. At this moment, no final conclusion can be drawn with regard to the origin and taxonomic status of these two isolates.

In 1995, Brasier et al. (8) suggested that a new Phytophthora species isolated from an Alnus sp. might be a hybrid. Recently Brasier et al. (5) analyzed several Phytophthora isolates from an Alnus sp. Except for the Swedish variants, all isolates possessed ornamented oogonia, a feature typical for P. cambivora. However, the alder Phytophthora isolates differed from $P$. cambivora by their homothallism, colony morphology, lower cardinal temperatures for growth, and unusually high chromosome numbers and dimorphic ITS arrays, especially in the UK variants. It was concluded that the UK variants represented a heterogeneous group of interspecific hybrids between a $P$. cambivora-like species and an unknown species closely related to $P$. fragariae.

$P$. meadii also was suggested to be a hybrid (24). Possible parental isolates were hypothesized to be $P$. palmivora and $P$. capsici or the heterothallic $P$. botryosa and the homothallic $P$. heveae, both of which occur on rubber trees in Southeast Asia. Brasier also suggested that $P$. citrophthora originated as a hybrid of $P$. nicotianae on citrus and $P$. capsici on cocoa (7). In the laboratory, hybrids were created between $P$. nicotianae and $P$. capsici by zoospore fusion (11). Some of the resulting hybrid isolates had an extended host range. Hence, it was hypothesized that interspecific hybridization in nature may result in extended host ranges. However, a reduced host range was found by Goodwin and Fry (15) in interspecific hybrids between $P$. infestans and $P$. mirabilis. Both of these results may be possible depending on the type of host-pathogen interaction involved. Our $P$. nicotianae $\times P$. cactorum hybrid isolates, from a Cyclamen sp., may be an example of extended host range, because neither of the parental species was reported on this host previously (13; Plant Protection Service, Wageningen, the Netherlands, unpublished data).

A detailed analysis of AFLP profiles revealed differences among hybrid isolates. Isolate PD 94/988 differed consistently from all other hybrid isolates, and this difference was also shown in the ITS-RFLP pattern. The ITS-RFLP bands of $P$. cactorum were weaker than the $P$. nicotianae bands, suggesting that isolate PD 94/988 had fewer copies of the ribosomal genes of $P$. cactorum. Isolates from the same host in most cases were more similar in AFLP profile to each other than to isolates from other hosts. This suggests that, dispersed as a clonal lineage, different hybrid isolates possibly specialized on different hosts. More data have to be collected to support this hypothesis. These differences indicate that the hybrid isolates may be not a single clonal lineage but, instead, may be the result of multiple hybridization events. Multiple hybridization events could be explained by the current sympatric occurence of Phytophthora isolates in Dutch horticulture. Phylogenetically closely related, but formerly allopatric, isolates of $P$. cactorum from Central Europe and isolates $P$. nicotianae from South America (9) can occur in such a system. More than one species of Phytophthora is often isolated from the same host or crop system (6), e.g., P. palmivora and P. megakarya on cocoa.

Phytophthora species are either homothallic or heterothallic, with two mating types, A1 and A2, in the latter case. Mating types are universal in that an A1 of one species is compatible with A2 of another species. Homothallic species contain at least one, but mostly both, mating hormones and their compatible receptors, and hence, outcrossing between homothallic species cannot be excluded theoretically. In fact, it has been proven that in homothallic $P$. sojae outcrossing actually does occur $(25,28)$. Hybridization, therefore, is possible between the heterothallic P. nicotianae and the homothallic $P$. cactorum. All hybrid isolates described in this paper are homothallic and, hence, produce oospores autonomously. Although abortive oospores were observed in all isolates, apparently significant numbers seem to be well developed. The fertility of the hybrid oospores is currently under investigation. Possible exchange of genetic materials in hybrid oospores may be an important factor in the evolution of natural Phytophthora populations. Nuclei of different ploidy levels may occur in the same mycelium as was shown for P. meadii (24) and may lead to genetic instability of the fungus. Our hybrid isolates showed AFLP patterns with an increased number of fragments compared

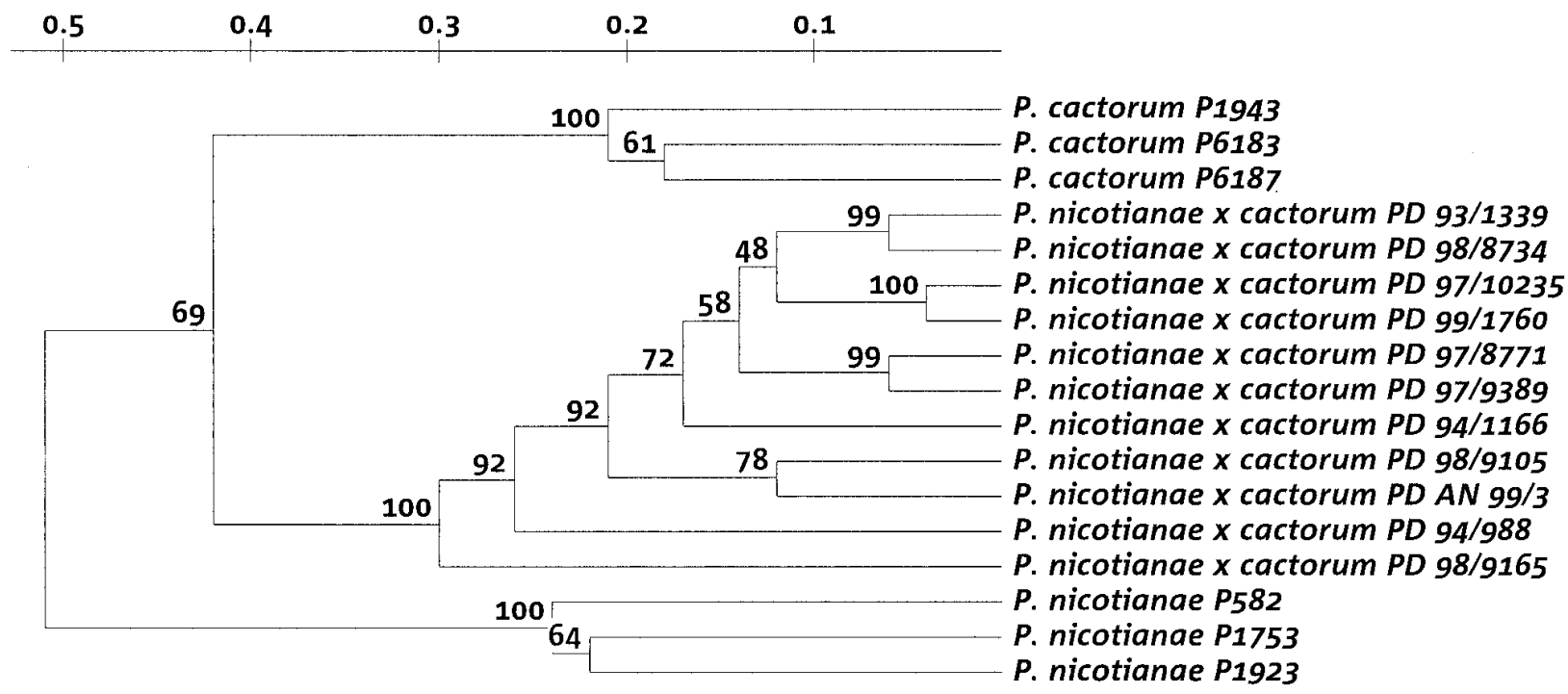

Fig. 7. Unweighted pair group method dendrogram constructed from 350 bands of amplified fragment length polymorphism fingerprint patterns of Phytophthora isolates with two primer combinations (E21×M16 and E20×M16) as shown in Figure 6. Distance scale (in fixed mutations per site) is drawn. Bootstrap values of 1,000 replications are shown in percentages above branches. 
with the parental isolates, which suggests polyploidy. The Alnus sp. isolates of Phytophthora also contained a greater number of AFLP bands (5) compared with single-species isolates suggesting different levels of ploidy.

The present paper has shown that natural $P$. nicotianae $\times P$. cactorum hybrid isolates do not belong to a single clonal lineage and may pose a serious threat to agriculture. Even a clonally spreading, single-hybrid isolate with a new host range may be fairly dangerous. For comparison, the migration of a single clone of the A1 mating type of $P$. infestans from the Americas to Europe in the 19th century caused tremendous damage all over the world (14). The danger would be even greater if the hybrid isolates were not of clonal origin. This is likely the case with the genetically diverse $P$. cambivora-like hybrid population from an Alnus discovered by Brasier et al. (5).

Also, it is risky to rely on one molecular technique to establish the identity of atypical Phytophthora spp. isolates. If, for example, one specific PCR primer set had been used, the hybrid isolates would have been misidentified. The existence of several Phytophthora species hybrids will undoubtedly complicate correct identification, particularly if new species hybrids are discovered in the future.

\section{ACKNOWLEDGMENTS}

We thank T. vd Bosch and I. Bontjer for their technical assistance. We also thank A. Numansen and A. Kerssies for performing the inoculation studies on Spathiphyllum plants.

\section{LITERATURE CITED}

1. Boccas, B. R. 1981. Interspecific crosses between closely related heterothallic Phytophthora species. Phytopathology 71:60-65.

2. Boccas, B., and Zentmyer, G. A. 1976. Genetical studies with interspecific crosses between Phytophthora cinnamomi and P. parasitica. Phytopathology 66:477-484.

3. Bonants, P. J. M., Hagenaar-de Weerdt, M., van Gent-Pelzer, M. P. E., Lacourt, I., Cooke, D. E. L., and Duncan, J. M. 1997. Detection and identification of Phytophthora fragariae Hickman by the polymerase chain reaction. Eur. J. Plant Pathol. 103:345-355.

4. Brasier, C. M. 1992. Evolutionary biology of Phytophthora. Part I: Genetic system, sexuality and the generation of variation. Annu. Rev. Phytopathol. 30:153-171.

5. Brasier, C. M., Cooke, D. E. L., and Duncan, J. M. 1999. Origin of a new Phytophthora pathogen through interspecific hybridization. Proc. Natl. Acad. Sci. 96:5878-5883.

6. Brasier, C. M., and Griffin, M. J. 1979. Taxonomy of 'Phytophthora palmivora' on cocoa. Trans. Br. Mycol. Soc. 72:111-143.

7. Brasier, C. M., and Hansen, E. M. 1992. Evolutionary biology of Phytophthora. Part II: Phylogeny, speciation and population structure. Annu. Rev. Phytopathol. 30:173-200.

8. Brasier, C. M., Rose, J., and Gibbs, J. N. 1995. An unusual Phytophthora associated with widespread alder mortality in Britain. Plant Pathol. 44:999-1007.

9. Cooke, D. E. L., and Duncan, J. M. 1997. Phylogenetic analysis of Phytophthora species based on ITS1 and ITS2 sequences of the ribosomal RNA gene repeat. Mycol. Res. 101:667-677.
10. Crawford, A. R., Bassam, B. J., Drenth, A., Maclean, D. J., and Irwin, J. A. G. 1996. Evolutionary relationships among Phytophthora species deduced from rDNA sequence analysis. Mycol. Res. 100:437-443.

11. Ersek, T., English, J. T., and Schoelz, J. E. 1995. Creation of species hybrids of Phytophthora with modified host ranges by zoospore fusion. Phytopathology 85:1343-1347.

12. Ersek, T., Schoelz, J. E., and English, J. T. 1994. PCR amplification of species-specific DNA sequences can distinguish among Phytophthora species. Appl. Environ. Microbiol. 60:2616-2621.

13. Erwin, D. E., and Ribeiro, O. K. 1996. Phytophthora: Diseases Worldwide. The American Phytopathological Society, St. Paul, MN.

14. Goodwin, S. B. 1997. The population genetics of Phytophthora. Phytopathology 87:462-473.

15. Goodwin, S. B., and Fry, W. E. 1994. Genetic analysis of interspecific hybrids between Phytophthora infestans and Phytophthora mirabilis. Exp. Mycol. 18:20-32.

16. Ilieva, E., Man in 't Veld, W. A., Veenbaas-Rijks, W., and Pieters, R. 1998. Phytophthora multivesiculata, a new species causing rot in Cymbidium. Eur. J. Plant Pathol. 104:677-684.

17. Lacourt, I., Panabières, F., Marais, A., Venard, P., and Ricci, P. 1994 Intraspecific polymorphism of Phytophthora parasitica revealed by analysis of mitochondrial DNA restriction fragment length polymorphism. Mycol. Res. 98:562-568.

18. Lee, S. B., and Taylor, J. W. 1992. Phylogeny of five fungus-like protoctistan Phytophthora species, inferred from the internal transcribed spacers of ribosomal DNA. Mol. Biol. Evol. 9:636-653.

19. Lilja, A., Karjalainen, R., Parikka, P., Kammiovirta, K., and Nuorteva, H. 1998. Pathogenicity and genetic variation of Phytophthora cactorum from silver birch and strawberry. Eur. J. Plant Pathol. 104:529-535.

20. Man in 't Velt, W. A. 1997. Restriction enzyme analysis of mitochondrial DNA of Phytophthora hybrids. Pages 92-95 in: Annual Report 1997 Diagnostic Centre Plant Protection Service, Wageningen, the Netherlands.

21. Man in 't Veld, W. A., Veenbaas-Rijks, W., Ilieva, E., de Cock, A. W. A. M., Bonants, P. J. M., and Pieters, R. 1998. Natural hybrids of Phytophthora nicotianae and Phytophthora cactorum demonstrated by isozyme analysis and random amplified polymorphic DNA. Phytopathology 88:922-929.

22. Nei, M., and Li, W. H. 1979. Mathematical model for studying genetic variation in terms of restriction endonucleases. Proc. Natl. Acad. Sci. 76:5269-5273.

23. Oudemans, P., and Coffey, M. D. 1991. Isozyme comparison within and among worldwide sources of three morphologically distinct species of Phytophthora. Mycol. Res. 95:19-30.

24. Sansome, E., Brasier, C. M., and Hamm, P. B. 1991. Phytophthora meadii may be a species hybrid. Mycol. Res. 95:273-277.

25. Tyler, B. M., Forster, H., and Coffey, M. D. 1995. Inheritance of avirulence factors and restriction fragment length polymorphism markers in outcrosses of the oomycete Phytophthora sojae. Mol. Plant-Microbe Interac. 8(4):515-523.

26. Van de Peer, Y., and De Wachter, R. 1994. Treecon for Windows: A software package for the construction and drawing of evolutionary trees for the Microsoft Windows environment. Comput. Appl. Biosci. 10:569570 .

27. Vos, P., Hogers, R., Bleeker, M., Reijans, M., van de Lee, T., Hornes, M., Frijters, A., Pot, J., Peleman, J., Kuiper, M., and Zabeau, M. 1995. AFLP: A new technique for DNA fingerprinting. Nucleic Acids Res. 23:4407-4414.

28. Whisson, S. C., Drenth, A., Maclean, D. J., and Irwin, J. A. G. 1994. Evidence for outcrossing in Phytophthora sojae and linkage of a DNA marker to two avirulence genes. Curr. Genet. 27:77-82. 